\title{
'Unrecognized victims': Sexual abuse against male street children in Merkato area, Addis Ababa
}

\author{
Getnet Tadele
}

\begin{abstract}
Background- Sexual abuse and exploitation of male children is one of the emerging social problems affecting the physical, social and psychological wellbeing of children in Addis Ababa. The magnitude of the problem seems much worse among the street boys because of their precarious living conditions. However, very little is known about the problem so far and it is apparently one of the least researched issue in the country.

Objectives- This paper explores the extent of the problem and reasons that expose children to sexual abuse around Merkato area, Addis Ababa.

Methods- The study employed a combination of quantitative (small scale survey) and qualitative methodology (indepth interviews, focus group discussions (FGDs) and case history interviews) involving a total of 221 children and key informants selected using convenient and snowball sampling.

Findings- Quantitative data revealed that about 28.6\% of male street children had been abused. Physical and mental immaturity of the children, secrecy and lack of awareness, use and abuse of drugs, the nature of street life, exposure to pornographic films and limited legal enforcement were found to be major reasons which predispose street boys to the risk of sexual abuse.

Conclusions- Sexual abuse against male children around Merkato area is rampant, but received less or no attention from concerned governmental and non-governmental organizations. Using child rights framework, the study suggested various preventive, protective and rehabilitative measures that should be taken to address the problem. [Ethiop. J. Health Dev. 2009;23(3):174-182]
\end{abstract}

\section{Introduction}

Sexual abuse has drawn the attention of researchers, policy makers, media and civil society organizations, indicating that not all sexual behaviors are voluntary and consensual. When it comes to children, any sexual act with a child is considered an instance of abuse/exploitation, with or without the child's consents to take part in the act. Different studies have identified child sexual abuse as "an all too common occurrence" regardless of social, economic or geographic boundaries (1).

There are some studies that show the existence of mento-men sex, and pedophilia including sexual abuse of male children in Addis Ababa (2-5). A study carried out on sexually abused boys in Addis Ababa depicted that there were 47 reported cases of sexual abuse of boys, which accounted for $22 \%$ of the total sexual abuse reported to the Police in 2004. Forty four percent of them were sexually abused by neighbors while $36 \%$ by strangers who had no acquaintance with victims. Out of those abused, $26 \%$ of the victims were street children (5). The same study indicated that all abusers were reportedly Ethiopians; and the vast majority (84\%) of them were never married. Another study carried out by Forum on Street Children Ethiopia (FSCE) on the situation of street children in eight major towns of Ethiopia revealed that out of all sexually abused children, males constituted $8 \%$ of the total in Addis Ababa. Similarly, 33\% of the girls and $12 \%$ of boys interviewed in Shashemene and Dilla towns reported that they had been raped (6). Still another study carried out in Addis Ababa confirmed that school boys and street children are found to be the primary victims of sexual assault (4).

The above victim based studies (2 - 5) are very scanty and our knowledge of the problem is very limited. Therefore, to date little is known about the magnitude, causes and effects of sexual abuse against male children and to what extent victim children have access to psychosocial and legal services. This study explores the social, economic and cultural context of sexual abuse against male street children and the ways in which these issues shape every day life of extremely vulnerable and largely inaccessible groups. Using multilevel perspectives and mixed methods, the study specifically sets out to address issues related to prevalence of sexual abuse against street male children and reasons that contribute to the incidence of sexual abuse in Merkato area, Addis Ababa, Ethiopia.

\section{Methods}

The study is a cross-sectional mixed methods combining qualitative (including participatory techniques) and quantitative methods to generate information from the study subjects. However, taking into account the existing socio-cultural taboos attached to sexuality and to minimize socially desirable responses, the study largely employed qualitative methods. 
Thus, two sets of instruments were developed and administered for the study. The first set of instruments constitute unstructured questions designed to serve as a guide for an in-depth interviews with male street children, key informants and focus group discussion participants. Four FGDs were conducted with street children using participatory tools (pair wise ranking, problem tree exercise, story telling and case presentations) to encourage maximum participation. One group was composed of female street children ${ }^{1}$. In the other two groups, younger (9-14 years) and older (15-18 years) male street children were treated separately assuming that sexual abuse experiences and coping mechanisms of each category could vary. The last group consists of both younger and older male street children together. The number of participants in each FGD ranged from 8-11 and 36 children took part in FGDs. Further, in-depth/life history interviews were conducted with 24 male street children. All informants were selected using convenience and snowball sampling method.

The second set of instruments consists of structured questionnaire (a small scale survey) administered to male street children who were identified through convenience and snowball sampling methods. One hundred twenty six male street children participated in interviewer administered questionnaire.

Overall, a total of 186 children aged from 9-18 years participated in the study and they represent diverse religious beliefs and family background. Five specific sites (the main cross-country bus terminal, Gojam Berenda, Mesalemiya, Sebategna and Atkilt Tera) were identified to access informants. In addition, 35 key informants working for different governmental and non governmental organizations were interviewed. The data were collected between January to March 2007.

The following table summarizes the different categories of informants involved in the study.

\footnotetext{
${ }^{1}$ Discussions were held with female street children (with child prostitutes) to obtain their reflections about male sexual abuse and how it affects their activity and sexual relationships with street boys.
}

Table 1: Different Categories of Study Participants, Merkato Area, Addis Ababa, 2007

\begin{tabular}{ll}
\hline Instrument/ method of data collection & \multicolumn{1}{c}{ Category of participants } \\
\hline Structured Questionnaire & Male street children \\
In-depth Interviews & Male street Children \\
& Male street children (younger age group 9-14) $\mathrm{n}=8$ \\
Focus Group Discussions & Male street children (older age group 15-18) $\mathrm{n}=11$ \\
& Male street children (mixed group) $\mathrm{n}=8$ \\
& Female street children group: $\mathrm{n}=9$ \\
& Region 14 Police Commission, Child Protection Units (CPUs) \\
Key Informant Interviews & from Arada, Addis Ketema, Lideta and Kolfe-qeranio sub-cities, \\
& First Instance Child Friendly Court, Regional Labor and social \\
& affairs Office, Addis Ketema sub-city, Emanuel Hospital, NGOs \\
& (FSCE, Child Abuse and Neglect Unit (CANU), Bright for children \\
& Voluntary Association, Child AID Ethiopia, AfricanNetwork for the \\
& Prevention and Protection against child Abuse and Neglect, End \\
& Child Prostitution, pornography and Trafficking for Sexual \\
& Purpose) \\
\hline
\end{tabular}

Overall total

\section{Data Analysis, Ethical Issues and Operational Definitions}

The issues raised include the magnitude of the problem, the reasons that expose to child abuse, impact of child abuse, ongoing efforts to tackle the problem and etc. Quantitative data were analyzed using the SPSS software package Version 11.0. With regards to the qualitative information, all the focus group discussion sessions and interviews were taped, transcribed, translated and entered into the computer for analysis. Transcriptions and other field notes were analyzed manually using contextual and thematic analysis (7).

The participants were informed about the purpose and significance of the study and informed verbal consent was obtained. They were further informed about the confidentiality of all the information and that they could refuse to answer any question when ever they feel uncomfortable ${ }^{2}$.

Unless otherwise stated, the term child for the purpose of this study refers to persons under the age of 18 years (8). Child sexual abuse is "any activity with a child before the age of legal consent that is for the sexual gratification of an adult or a substantially older child. These activities include oral-genital, genital-genital, genital-rectal, handgenital, hand-rectal, or hand-breast contact; exposure of sexual anatomy; forced viewing of sexual anatomy; and showing pornography to a child or using a child in the production of pornography"(9). When operationally defined, the study considered only the following two categories of male street children between the ages of 9- 
18 and live or work on the streets around Merkato area: children on the street refers to those street children who are primarily engaged in economic activities of the street, while living with their parents or relatives and children of the street refers to children who are both economically and socially engaged in the street life. These children live and work on the streets without any kind of control or assistance from parents or relatives (10).

\section{Results}

\section{Sexual Abuse Encounters}

As indicated in the table below, out of the total number of respondents who completed the questionnaire, 36 (28.6\%) reported that they had encountered different types of sexual abuses in their lives. On the contrary, the vast majority $90(71.4 \%)$ reported that they had never experienced any form of sexual abuse whatsoever.
However, given the sensitive nature of the problem and the way of life of the street children, it is logical to expect that sexual abuse would be much higher than reported. Data obtained from qualitative methods vividly substantiates this argument. During focus group discussions held with male street children, the participants were asked to list down and prioritize the major types of abuses/dangers they encounter in their daily lives according to degree of severity and frequency of occurrence. Accordingly, both categories of children identified sexual abuse as their major concern. It was ranked on the top list (second and third) as perceived by the younger and older children groups respectively.

\footnotetext{
${ }^{2}$ All names used in this report are pseudonyms.
}

\begin{tabular}{|c|c|c|c|}
\hline Description & Classification & Total & Percentage \\
\hline Age & $\begin{array}{l}9-12 \\
13-15 \\
16-18\end{array}$ & $\begin{array}{l}26 \\
54 \\
46\end{array}$ & $\begin{array}{l}20.6 \\
42.9 \\
36.5\end{array}$ \\
\hline Educational level & $\begin{array}{l}\text { Never attended } \\
1-4 \\
5-8 \\
9-10\end{array}$ & $\begin{array}{c}26 \\
46 \\
52 \\
2\end{array}$ & $\begin{array}{c}20.6 \\
36.5 \\
41.3 \\
1.6\end{array}$ \\
\hline Place of origin & $\begin{array}{l}\text { Addis Ababa } \\
\text { Outside Addis }\end{array}$ & $\begin{array}{l}42 \\
84\end{array}$ & $\begin{array}{l}33.3 \\
66.7\end{array}$ \\
\hline Living arrangement & $\begin{array}{l}\text { alone } \\
\text { with parents } \\
\text { with relatives } \\
\text { with peers } \\
\text { on the street }\end{array}$ & $\begin{array}{c}6 \\
22 \\
14 \\
8 \\
76\end{array}$ & $\begin{array}{c}4.8 \\
17.5 \\
11.1 \\
6.3 \\
60.3\end{array}$ \\
\hline $\begin{array}{l}\text { Length of time spent on } \\
\text { street }\end{array}$ & $\begin{array}{l}<1 \text { year } \\
1-3 \text { years } \\
3-5 \text { years } \\
>5 \text { years }\end{array}$ & $\begin{array}{l}16 \\
48 \\
52 \\
10\end{array}$ & $\begin{array}{c}12.7 \\
38.1 \\
41.3 \\
7.9\end{array}$ \\
\hline Reason for joining the street & $\begin{array}{l}\text { death of parents } \\
\text { Conflict within the family } \\
\text { parent's harsh treatment } \\
\text { peer influence } \\
\text { family poverty }\end{array}$ & $\begin{array}{l}36 \\
18 \\
26 \\
16 \\
30\end{array}$ & $\begin{array}{l}28.6 \\
14.3 \\
20.6 \\
12.7 \\
23.8\end{array}$ \\
\hline & Total & 126 & 100.0 \\
\hline
\end{tabular}

The key informants also pointed out that the magnitude and gravity of sexual assault on boys is increasing in the city at frightening rate. When asked the percentage of boys abused sexually from the sexual assault committed on 10 children, the key informants from CANU estimated that 4 out of every 10 children are boys (although this varies from one month to another). They added that those boys who are mainly exposed to this problem are street children where as the perpetrators could be from different walks of lives. The key informants further argued that the culprits go to the streets where these children sleep and seduce them via trickery and offering different kinds of gifts, and rape them at the end.

Table 3: Number of Sexually Abused Male Street Children Known by the Respondents, Merkato Area, Addis Ababa, 2007

\begin{tabular}{lcc}
\hline \multicolumn{1}{c}{ Classification } & Total & Percentage \\
\hline One child & 41 & 32.6 \\
2-5 children & 28 & 22.2 \\
More than 5 children & 11 & 8.7 \\
Don't know & 46 & 36.5 \\
Total & 126 & 100 \\
\hline & $\mathbf{1 2 6}$ & $\mathbf{1 0 0 . 0}$ \\
\hline
\end{tabular}

Ethiop. J. Health Dev. 2009;23(3) 
The findings also indicated that, out of 126 children, $64 \%$ of them explained that they knew some children who were sexually abused in their concentration cites or other parts of Merkato. When this figure is disaggregated in terms of number of children they knew, $32 \%$ of them knew at least one who encountered sexual abuse, 22\% knew about 2-5 children and $8.7 \%$ knew as many as five children and more. On the other hand, 37\% explained that they do not know any sexually abused child.

The key informants involved in the study asserted that the children who are under 15 years and newcomers to the street life are more likely to be abused compared to older children. They are targeted because of their lack of ability to defend themselves, and their relative gullibility. However, they are the ones who report immediately when they are sexually abused.

Markos [16 year old street boy] who experienced an attempted sexual abuse in the first few days of street life indicated how the newcomers become easy prey by taking his own experience as an example.
Most often, it is the newcomers and younger children who are most vulnerable. When I came to Addis two years back, everything was new for me. I did not know anyone in the city and had no options except joining street life. Fortunately, I got two children who speak Tigrigna. They were from the area I came from. I slept with them for two days on the street. On the third day, an old man came to our sleeping place and asked to sleep with us. We welcomed him. I never expected any thing to happen. I was napping and the man was waiting until I fell asleep. Just after a few minutes, the man started putting off my trouser. I thought that he was trying to share my night cloth. I pretended as if I were asleep. In the mean time, I whispered to my friends on ears what the man was trying to do. As soon as I told them they stood up and they realized that the man was trying to abuse me. Had they told me earlier, I could have avoided the man from the outset. They kicked him out from the area. My friends told me that many street boys particularly newcomers have experienced sexual abuse. Since that day, I am aware of the existence of sexual abusers and started protecting myself from such abuse.
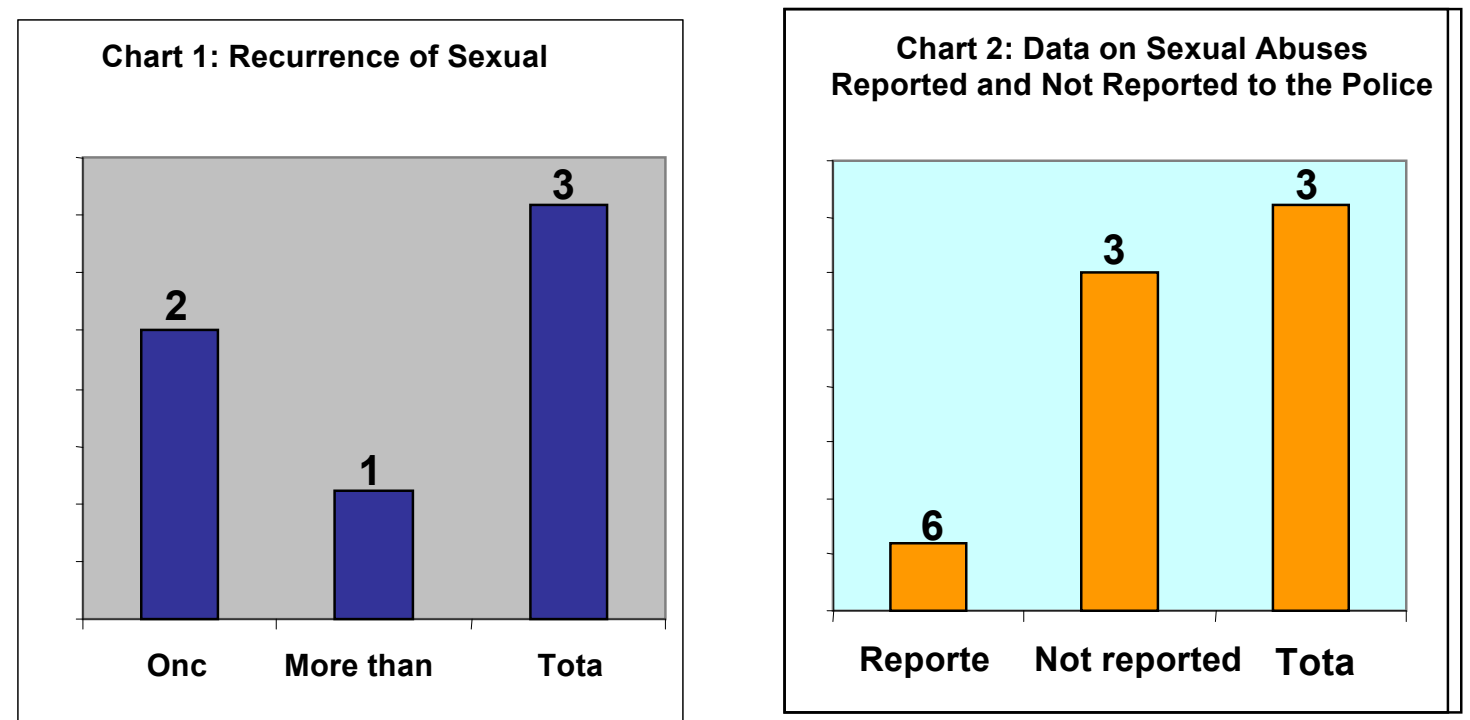

Figure 1: Recurrence of Sexual Abuse and Reporting to the Police among Male Street children, Merkato, Area, Addis Ababa, 2007

Data in chart 1 depicts frequency of sexual abuse encountered by male street children. A large proportion of abused children (25/36) reported that they had been abused only once, the rest (11/36) reported multiple episodes of abuse. Some children underscored that sexual abuse and street life are inseparable elements. For instance, a 17 year old boy who lived eight years on the street reported: Though every street boy conceals the matter, no one escapes abuse. To my knowledge, all our group members (friends) here around 'Gojam Berenda', have encountered sexual abuse at least once.
Chart 2 also shows that substantially large percentage of abused children hardly reported the case to the police (only 17\% of the children reported seeking legal support). Qualitative data revealed that such lower tendency of reporting sexual abuse was due to fear of stigmatization, retribution of the perpetrators or lack of trust in the legal process and law enforcing bodies. The following anecdote from Yohanes (16 year old victim) substantiates this assertion:

...No, I did not report. I had three main reasons. First, I did not know where to report as I was new to the city. Second, I did not want to make the case known by 
everybody for fear of stigma and discrimination. I mean I felt harassed for being abused and when people started calling me bushiti [derogatory name for homosexuals].
Third, even if I report the case to the police, I heard that the police do not see the issue of male sexual abuse seriously.

Table 4: Types of perpetrators as Identified by Male Street Children, Merkato Area, Addis Ababa, 2007 Description Classification $\quad$ Total Percentage

\begin{tabular}{llcc}
\hline Identified Perpetrators & Foreigners/Diaspora & 8 & 6.3 \\
& Peers/friends & 59 & 46.8 \\
& Relatives/guardians & 14 & 11.1 \\
& Police & 5 & 4.0 \\
& Bar owners & 6 & 16.8 \\
& Strangers & 21 & 10.3 \\
& Others & 13 & $\mathbf{1 0 0}$ \\
\hline
\end{tabular}

The respondents were also asked about the category of perpetrators (those people mostly involved in male sexual abuse). The findings showed that peers/friends were found on the top list of abusers as reported by $47 \%$ of the children, followed by unknown persons/strangers (17\%), relatives $(11 \%)$ and $10 \%$ students and rich businessmen (reported under others category). Foreigners/Ethiopian Diaspora, bar owners and police were reported by $6 \%$, $5 \%$ and $4 \%$ of the respondents respectively.

Another finding is that $25 \%$ of the sexually abused male street children were abused by their friends/peers and this shows that street children themselves are involved in the practice. According to the in-depth interviews and FGDs, the children stated that there are number of street children involved in sexual abuse of male street children. These are children, for various reasons, who have experienced sexual abuse or exploitation at a certain point in their lives and have developed attraction to same sex, they argued. No one expects them as abusers in their first day of coming to the group/street. They maintained that these children are expelled from other places due to their "bad" behavior. But once they are known to be abusing any street child, they will be expelled the next day from their "territory/area". The only option they have is either to find their partners in the community or leave the area and continue abusing others in a place where they are not well identified. They move from place to place and from one town to another. Experience has taught street children that, unless they know each other very well, they never trust newcomers.

Some participants of the study identified rich men and elderly among the top list of people involved in sexual abuse and exploitation of male street children. The following anecdote from FGD participants substantiates this claim.

Most abusers are rich men. Most of them often come at night to our sleeping place with their beautiful cars. As usual, if a man wants to have sex with one of the street children, he knows what our needs are (basic survival need) and he tries to persuade us by giving money. Abusers know very well that we are starved i.e. no adequate food, cloth, and shelter. We often say that hunger or starvation is much worse than war. Some also pretend as if they were sympathetic and ready to help us get out of street life. They even offer us biscuits and cloth just to trick our mind. The common mechanism they often use to deceive us is they promise to find us a job and let us live with them. If we agree to go with them, they take us to hotels rooms. When we arrive at the hotel rooms, they openly tell you to enjoy in the room. At this juncture, we understand their hidden motive. If you are a newcomer, you can easily be cheated. And some openly ask you to have sex with them before even going to the hotel (Biruk, a 16 year old boy).

Ideally, the police are among the duty bearers, responsible for the legal enforcement of rights of children in general, and street children in particular as clearly put forth in the Child Rights Convention (CRC). Beyond chasing away street children at night from their sleeping places, some police officers are said to be involved in abusing street boys sexually. One of the interviewees [Akale, 17 year old street boy] who experienced an attempted sexual abuse by a police officer said the following:

It was during the post election period when street protests and robbery were frequent events. Many children and youths including street children were being chased away by the police and security guards. The police and security guards were in every corner of Addis Ababa.... One day it was around mid night, three police members came to our sleeping place around bus station. One of the police members started handing out biscuits to us. He pretended as a passionate person. In the mean time, he came closer and asked me where I came from and whether we indulge in sex with our boyfriends. This was so strange for me because I never expected this question from him. I thought that he was to accuse us and detain. Then he expressed his desire to have sex with me. He promised to give me money and to buy me a meal or

Ethiop. J. Health Dev. 2009;23(3) 
cloths. I had nothing to say and appeared willing, because I realized that he is much stronger than me. I was thinking of how I could escape from that dangerous situation. Meanwhile, something came to my mind which I hoped to convince him at least to stay away for sometime. I told him that I wore two trousers and had to take them off. He was waiting till I took off my trousers. Then I ran away fast with determination and without looking back and arrived at Mesalemia area. When I realized that the man was not following me, I slowed down. This was the terrible experience that had made me aware of protecting myself from sexual abuse.

Some key informants revealed not only the involvement of police and other officials in abusing male children but also how the investigation process against abusers is thwarted due to the influence of powerful government officials involved in men-to-men sex. Here is the verbatim story from one police officer working for CPU:

You are forced not to go further [in the trial process] by some pertinent officials after you have reached some stage. There are officials that order you to stop your investigation at some level. They are officials and authorities who are involved in this life. You can't go further. It is really tough. We can say that some policy makers, politicians and officials are involved in men-tomen sex. Since they are involved they want this kind of life to continue as much as they can. There is every possibility of denying a necessary support to those who follow the case and obstruct other efforts to tackle the problem from the grassroots.

The Director of one local NGO also voiced the same complaint. He even went on and said that he had been harassed by some officials for his work/activism against sexual abuse of male children ${ }^{3}$.

\section{Reasons that Expose Male Street Children to Sexual Abuse}

In order to address the problem of sexual abuse, it is necessary to comprehend why sexual abuse occurs. Respondents were asked to identify some factors that made male street children vulnerable to sexual abuse in addition to the fact that these children live on the streets without guardians. The other contributing factors identified by different groups of informants involved in the study are discussed hereunder.

Immaturity of children

Some informants attributed sexual abuse of male children to immaturity of children on the one hand and illegality of homosexuality on the other hand.

Since homosexuality in Ethiopia is culturally and religiously condemned illegal practice, there seems to be a strong resistance and low acceptance among the society, even though, the practice is spreading underground. This would mean that homosexuals often find it difficult to approach adults for fear of the presumed resistance. As a result, they resort to childrenwho are not physically and mentally strong to fight back abusers.

Exposure to pornographic videos/films

Informants in every discussion emphasized the impact of pornographic films as one of the major factors fueling the practice. In an individual interview, a 14 year old street boy (Abraham) expressed ${ }^{4}$

When I came to Addis two years back, I heard a new term "bushti" and the first time I heard the word, I asked my friend what it meant and he told me that it means a man having sex with a man. I was shocked because, at that time, it was so strange for me. A few days later the same friend invited me to one of the video houses in slums of Merkato to show me how 'bushtiwoch' (plural for bushti) practice sex...

Pornographic videos/films or magazines give wrong message particularly for abused children who are already in confusion about their sexual orientation. It helps them assimilate themselves into the practice assuming it as a 'normal' and even a more 'civilized' sexual practice. The director of one of the NGOs working on the protection of street children remembered the case of Kedir, 14 year old street boy who had been raped by two brothers at the same time. The informant explained that:

In a counseling session, the child disclosed that he was in confusion in the aftermath of abuse. He used to ask himself 'am I a female? How on earth men go for sex with boys'? But later on he found the 'answer' to his persistent questions from the video house when he watched men having sex with men. The confusion was cleared away and the child upheld that it is a normal behavior and he himself kept on practicing it with small boys.

\section{Economic reasons}

It was recurrently mentioned by participants during interviews and FGDs that street children particularly young newcomers are easily deceived by adult men for minor gifts or little money. Street children have difficulty of fulfilling their minimum survival needs (daily bread, clothing, and shelter). Almost all of the street children are addicted to smoking and chewing khat. For some street boys, having sex with men is a means of earning money to fulfill basic survival needs and satisfy habits. It was pointed out that there are some male street children who keep regular sexual partners/customers indicating the growing number of sexually exploited boys. Besides, it was noted that children from impoverished families such as street children can be sexually assaulted while they are selling cigarettes or khat around night clubs/bars in the 
middle of the night and this is another ramification of poverty

Substance use and abuse

Addiction to alcohol and various drugs such as khat and sniffing glue is also mentioned as one major reason contributing to increased prevalence of sexual abuse and exploitation of male street children. As indicated above, most of the street boys chew khat, smoke cigarettes and drink alcohol. Drug use is common among both abusers as well as victim children. Abusers persuade the children to drink to the level that they lose their self control. Some street boys were raped when they lost control of themselves after using various substances particularly 'ganja' (marijuana), widely used drug among street children.

Street life: lack of shelter

Most of street children take their shelter in public spaces and live without attention, support and control of caretakers. Thus, the context of the street life (lack of shelter) was cited as one of the main reasons which made them vulnerable to sexual abuse. Some of them wander around during the night time out of fear of abuse and sleep during the day. As Kasahun (14 years old street boy and victim of sexual abuse) said: All male street children have experienced sexual abuse at least once particularly in the first weeks of their arrival. No one can escape such kind of abuse while living on the street and safety is unthinkable in the street environment.

Availability of obscure hotels, liquor houses and rooms to be rented in abundance in Merkato area intensifies the vulnerability of male street children and create a convenient setting for perpetrators to target children with limited public scrutiny. In addition, frequent physical proximity of boys on the street and their culture of sharing and sleeping together in public space or in rented rooms may contribute to a gradual sexual contact with each other.

\section{Secrecy, lack of awareness and attention}

It was pointed out that newcomers are among the most vulnerable group of street children to sexual abuse. As most of them had no information about male sexual abuse, they hardly take necessary precautions when they start street life. This is mainly connected to the secrecy and stigma that surrounds men-to-men sex and sexual abuse against male children. The problem of male sexual abuse is not yet part of the public discourse. Unlike sexual abuse against girls, parents may not be preoccupied with the dangers of sexual abuse their sons could face. Therefore, male children are not well informed about the existence of men-to-men sex and the precautions they should take from pedophiles and other abusers.
One key informant from one of the NGOs illustrated how the issue is shrouded in secrecy and the resistance they confronted with the community when they tried to expose those who abused male children. She said:

We faced a serious challenge from our target community initially when we begin to report suspected abusers (members of that particular community) to the police. Outraged by our decision, family members of the abusers and neighbors all around came to our office, yelled at us and condemned our effort of exposing such a shameful act, for it casts bad reputation in the community. Some of them even demanded us to drop the charge.

Another key informant from Region 14 CPU also attested that the absence of open discussion about the issue within the family environment could be one of contributing factors to sexual abuse against male children. Children are subject to sexual abuse by some of their family members and the case usually remains unearthed. This informant maintained that not talking about the issue within the family circle presents an enormous challenge to mitigate the problem of sexual abuse.

When the key informants were asked about the attention given to the problem by governmental and nongovernmental organizations, they all unanimously replied that enough has not been done. A police officer narrated in the following words:

I can't say both governmental organizations (GOs) and non-governmental organizations (NGOs) have participated to tackle this problem. Once, Ethiopian television (ETV) showed us a glimpse of this case. ETV aired the testimonies of the children who were sodomized by force by shrouding their face. But, the society hasn't done enough to avert the situation except cursing it. There has not been any effort that has been done to create the awareness about the situation in the society. ... Many under age boys are being assaulted sexually. Actually, it is getting worse. The Media did not play their own part to tackle the problem either. They are talking about the assault inflicted on women only, but the assaults inflected on men, which is ignored by Media and other pertinent institutions is increasing at frightening rate. I don't think the necessary measure to tackle the problem has been taken.

Another informant (social worker) also echoed the above informant's position.

I would say everybody feels bad when they hear such disgusting crime. But, there is no any tangible movement to tackle this problem from the pertinent bodies as well as from law makers. When we invite government officials who have direct relation with the issue for a meeting, they usually fail to come to address this issue. They rather send their representatives. I have also come

Ethiop. J. Health Dev. 2009;23(3) 
across officials and policy makers who hate the whole issue and curse why they are invited on such events.

One can argue that such kind of resistance from the community and concerned bodies is an outcome of limited awareness on the problem. Under such persistent silence, it is the children especially street boys who are at risk of being abused and bear the brunt of the problem when abused.

\section{Limited legal protection}

The response of law enforcing bodies towards sexual abuse of street boys still seems lukewarm. In all the discussions, children unanimously expressed their dissatisfaction with the limited protection given from police forces and repeatedly voiced a sense of insecurity. One street boy expressed his dismay with the police offers as follows:

In my view, the law enforcement process is not promising. Since the police are corrupt, perpetrators are usually released the next day. Amazingly, the police do not accept street children as witnesses because they are considered as liars. When we experience sexual abuse, we used to report to the police. But the police members do not trust us and don't accept whatever we say. They consider it as we engaged in consensually for financial or material benefits (Asmelash, 17 year old street boy).

The above stories were further substantiated by the responses of the police officers participated in the study. They admitted lack of conducive and child friendly reporting mechanism in the police stations. Other police officers, however, rejected such allegations:

Of course, there are situations that scare children to report what happened to them to the police. I think the first reason is because they feel ashamed to explain the offence committed on them plainly. Second, they don't want to stop this life. I mean, they would like to continue having sex with men as the money earned from men-tomen sex enables them mitigate their day to day problems. The other reason is that they become hooked by homosexual life. I think they need a medical treatment to get out of this life.

The above narrative seems to be tantamount to blaming the victims. Such victim-blaming approach discourages survivors of sexual abuse from reporting the incidence or seeking treatment. The researcher, however, understands that it is always difficult to convict perpetrators beyond reasonable doubt as sexual offence takes place in the absence of witnesses. This creates enormous challenge and frustration among law enforcers while dealing with sex offenders or sexual abuse.

\section{Discussion}

The forgoing discussion revealed that a lot of male street children have been sexually abused and given their precarious situation on the street; they are likely to be abused in the future. What is more, the issue remains largely unreported, under-reported or misreported partly because of a widespread public and religious belief that claims men-to-men sex or male sexual abuse is not Ethiopian. Lack of reporting creates a situation where it is difficult to quantify the magnitude of the problem. It also led to lack of focused attention and action to address sexual abuse of these children by concerned organizations. As a result, there are no specific programs devised and implemented that take account of male street children's experiences related to sexual abuse. Almost all of the street children and key informants involved in this study indicated that, sexual abuse of street boys is increasing from time to time though the issue has not received the attention it deserves from the government as well as civil society organizations.

The study indicated that the root causes that expose male street children to sexual abuse are multifaceted and complex. Thus, in order to tackle the problem and bring about a long lasting change and improvement in the life of street children, it is commendable to follow a multidimensional and integrated developmental approach. This would mean that attention needs to be given for a holistic intervention involving prevention/protection advocacy and rehabilitation strategies from the rights based perspective, so that all concerned duty bearers would exert maximum effort to address the problem. Therefore, supportive national policies based on human rights are needed to ensure appropriate response to the plight of street children. In a word, any effort to care and support them should be based on human rights principles, CRC, and African Charter on the Rights and Welfare of the Child, such as their right to education; information; protection against child labor and separation from parents and siblings; health care of the highest level available; non-discrimination and equality before the law; participate fully in public and cultural life; associate freely with others and express opinions; and protection against sexual, physical and emotional abuse.

Unless immediate preventive and protective measures are taken to check the spread of the problem, it will immensely endanger the rights of survival and development of children enshrined in the CRC. There is a need to deconstruct the notion that the sexual abuse and exploitation of boys is non existent or occurs rarely. Newcomers (from rural areas in particular) join the street with the hope of getting money by engaging in some kind of work. Most of them never give it a first, let alone a second, thought for possibility of being sexually abused. 
If they are informed about the possibility of encountering sexual abuse and how they could protect themselves from such attack, there is a possibility to minimize the risk of abuse. The secrecy and silence of the public concerning male sexual abuse need to be broken through various awareness raising strategies. Working with the mass media will play enormous role for advocacy and reaching a wider population, particularly children. It is also necessary to provide a road-side awareness/information to street children on how to protect themselves from sexual abuse, about legal protective measures, assertiveness skills and other strategies using peer educators.

Establishing and strengthening integrated rehabilitation/recovery services and referral systems should be considered while working along with the preventive measures. Both the victims and the child offenders need to be counseled. Child friendly centers where street children (regardless of sex and abuse status) get access to recreation, information, medical services, counseling and legal aid services need to be established. As isolated programs and labeled institutions reinforce stigmatization, such a holistic approach is believed to be preferable to facilitate an effective recovery and rehabilitation of victims of sexual abuse. Further, alternative means of income need to be sought for those male children who are exposed to commercial sexual exploitation. They need to be provided with counseling support, skills training and access to financial sources, so that they will be able to engage themselves in other income generating activities.

In conclusion, it is hoped that this research sheds light for understanding the stereotyped gender construction which views girl children as the only vulnerable group to sexual abuse and exploitation. This study may inspire immediate male children inclusive action by NGOs and GOs entrusted to protect the rights of children. The study may also inspire other large scale quantitative and qualitative studies on this emerging social problem not only in Addis Ababa but also in other regional towns and cities to see if the situation is prevalent outside of Addis Ababa as well.

\section{Acknowledgements}

The author would like to thank Forum on Street Children-Ethiopia (FSCE) for financially supporting the research upon which this article is based. However, the views expressed in this paper are those of the author alone, and not of the funding agency. Special thanks to
Desta Ayode for his unreserved support. Desta was more than a research assistant and was equally committed to the success of the study. The author would also like to thank the key informants and children who took part in the study and Woldekidan Kifle for his comments.

\section{References}

1. Wyatt GE, Newcomb MD, Riederle MH. Sexual Abuse and Consensual Sex. Women's Developmental Patterns and Outcomes. London: SAGE Publications; 1993, P.40.

2. Ero D. Sexual Abuse of Male Children in Addis Ababa. M.A. thesis, School of Social Work, Addis Ababa University; 2007.

3. Tefera A. Sexual Abuse against Male children in Addis Ababa. B.A. thesis, Department of Sociology and Social Anthropology, Addis Ababa, University; 2007.

4. Hagos S, Haile Mariam D. Assessment of HIV/AIDS related risks among Men Having Sex with Men (MSM) in Addis Ababa, Ethiopia. Journal of Public Health Policy 2009; 30(3):269-279.

5. Hagos B. Sexual Abuse and Exploitation of male children in Addis Ababa. Save the Children, Denmark and Bright for Children Voluntary Association, Addis Ababa, 2006.

6. FSCE. The situation of street children in eight major towns of Ethiopia Unpublished research report, Addis Ababa, 2003.

7. Miles MB, Huberman AM. Qualitative Data Analysis (2nd edition). Thousand Oaks, CA: Sage Publications, 1994.

8. United Nations Convention on the Rights of the Child (CRC): Article 1; 1989.

9. Johnson CF. Child Sexual Abuse (Review). Lancet 2004; 364 (9432): 462-70.

10. Ministry of Labor and Social Affairs (MOLSA). The national study on street children: Nature and magnitude of the problem and methods of intervention. Addis Ababa, 1995.

\footnotetext{
${ }^{3}$ By saying all these, the researcher is not by no means equating homosexuals with pedophiles although the informants seem to have difficulty in distinguishing the two sexual practices.

${ }^{4}$ It should be noted that exposure to pornography is a form of sexual abuse (Johnson, 2004). Thus, exposure to pornographic films is abuse of children and contributing factor to abuse as well.
} 

Department of Sociology, Addis Ababa University, P.O. Box 150374, Addis Ababa, Ethiopia, E-mail: gtadele@sosa.aau.edu.et 